\title{
Culturally Responsive Teaching: A Framework for Educating Diverse Audiences ${ }^{1}$
}

\author{
John Diaz, Cecilia Suarez, and Laura Valencia ${ }^{2}$
}

\section{Abstract}

As the diversity of Extension clientele continues to grow, it is important for Extension educators to consider new ways of supporting this population. The purpose of this article is to provide a framework for educating diverse audiences to assist in helping these audiences attain the learning outcomes of Extension education programs. This includes: (1) acquiring a knowledge base of diverse cultures, (2) designing or utilizing culturally relevant curricula, (3) utilizing cultural caring and developing a learning community, (4) practicing intercultural communications, and (5) establishing cultural congruity in classroom instruction.

\section{Introduction}

As immigration continues to expand and shape the changing demographics in the United States, Extension clientele are becoming more diverse. According to the Pew Research Center, there were a record 44.4 million immigrants living in the United States in 2017 that accounted for $13.6 \%$ of the nation's population (Radford \& Noe-Bustamante, 2019). This represents more than a fourfold increase since 1960, when only 9.7 million immigrants lived in the United States, accounting for just $5.4 \%$ of the total US population (Radford \& Noe-Bustamante, 2019).

These immigration trends are expected to continue in the United States, with Hispanics accounting for the largest proportion of growth. The US Hispanic population reached a record 59.9 million in 2018, which was 1.2 million more than the previous year and up from 47.8 million in 2008 (Flores, Lopez, \& Krogstad, 2019). Hispanics accounted for $52 \%$ of all US population growth from 2008 to 2018 (Flores, Lopez, \& Krogstad, 2019). The large Hispanic population in the United States represents a challenge for Extension educators, especially in states with large Hispanic populations, such as California, Florida, New Mexico, and Texas, to utilize culturally responsive teaching (CRT) so Extension can provide culturally relevant programs.

\section{Culturally Responsive Teaching}

The purpose of this article is to outline a framework for culturally responsive teaching developed by Geneva Gay (2018), a renowned expert highly decorated in the field of multicultural education. This framework can be applied not only to Hispanic populations but to all ethnic and racial minority groups (see figure 1). CRT is a pedagogy that recognizes the importance of including students' cultural identities in all aspects of learning and empowers them socially, intellectually, politically, and emotionally (Banks \& Banks, 2009; Gay, 2002; Nieto \& Bode, 2007). Experts assert that programs that do not consider the cultural differences of their students are frequently less effective (Gay, 2002; McGee \& Banks, 2009; Nieto \& Bode, 2007). A gap currently exists between wanting to educate diverse audiences and being prepared to do so. According to Gay (2002), "too many teachers are inadequately prepared to teach ethnically diverse students" (p. 106).

1. This document is AEC678, one of a series of the Department of Agricultural Education and Communication, UF/IFAS Extension. Original publication date October 2019. Visit the EDIS website at https://edis.ifas.ufl.edu for the currently supported version of this publication.

2. John Diaz, assistant professor and Extension specialist, program development and evaluation; Cecilia Suarez, assistant professor, Department of Agricultural Education and Communication; and Laura Valencia, Extension agent I, UF/IFAS Extension 4-H Youth Development Program, UF/IFAS Extension Osceola County; UF/IFAS Extension, Gainesville, FL 32611.

The Institute of Food and Agricultural Sciences (IFAS) is an Equal Opportunity Institution authorized to provide research, educational information and other services

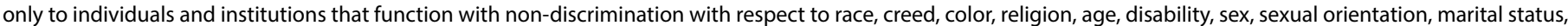

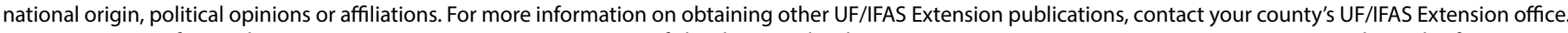
U.S. Department of Agriculture, UF/IFAS Extension Service, University of Florida, IFAS, Florida A \& M University Cooperative Extension Program, and Boards of County Commissioners Cooperating. Nick T. Place, dean for UF/IFAS Extension. 


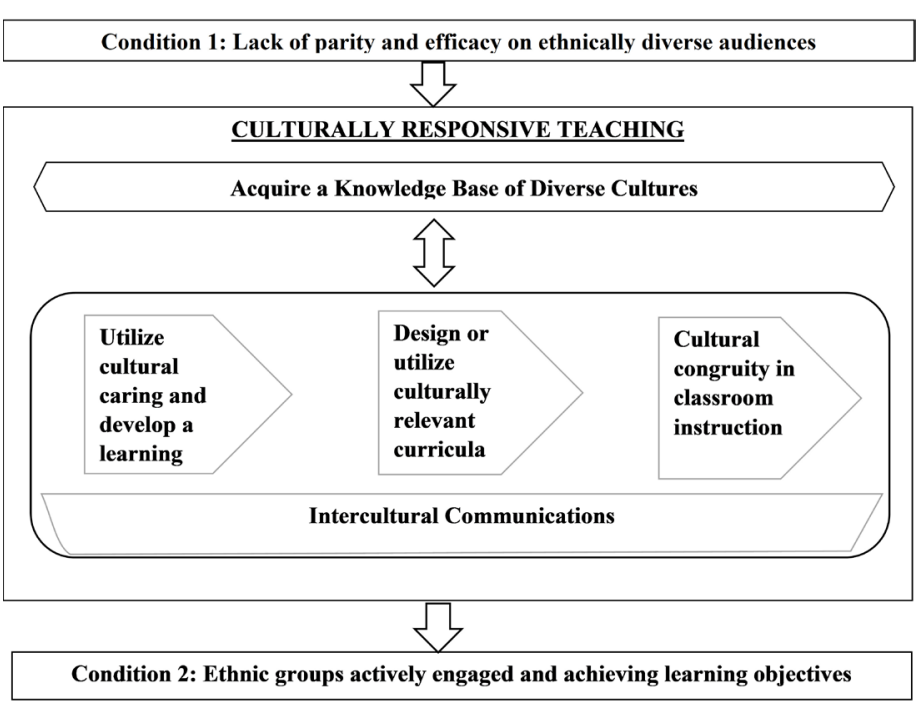

Figure 1. Framework for Culturally Responsive Extension Programs

\section{Knowledge Base of Diverse Cultures}

It is imperative that educators have explicit knowledge of cultural diversity to meet the needs of ethnically diverse students (Gay, 2002). According to Gay (2002), there are three key pillars to achieving the knowledge base necessary to enhance culturally responsive teaching. These are:

\section{Understanding the cultural characteristics and contribu-} tions of different ethnic groups (Hollins, King, \& Hayman, 1994; King, Hollins, \& Hayman, 1997; Pai, 1990; Smith, 1998). This includes cultural values, traditions, learning styles, contributions, and relational patterns.

\section{Acquiring detailed, factual information about the cultural} particularities of specific ethnic groups. This may include the contributions that different ethnic groups made to their subject areas to incorporate into programming.

\section{Gaining more knowledge about the contributions of various} ethnic groups to a range of disciplines and multicultural education research, scholarship, and theory. There is no shortage of materials and resources that explain these contributions that can be utilized by Extension educators. Gay (2002) recommends that all teachers take courses or trainings on the contributions of ethnic groups to content areas that they will teach.

\section{Culturally Relevant Curricula}

There are typically three types of curricula that are used for teaching cultural diversity. These include:

\section{Formal plans for instruction. Formal plans of instruction} are those that are approved by UF/IFAS Extension. These formal plans are typically accompanied by textbooks and curriculum guides issued by national, state, or local organizations. Extension educators need to evaluate the multicultural strengths and weaknesses of the curriculum and instruction design. They should make changes to improve its quality and relevance for diverse audiences. Gay (2002) explains that educators need to evaluate "quantity, accuracy, complexity, placement, purpose, variety, significance, and authenticity of the narrative texts, visual illustrations, learning activities, role models, and authorial sources used in the instructional materials" (p. 108).

2. Symbolic curriculum. Gay (2002) explains that a symbolic curriculum includes "images, symbols, icons, mottoes, awards, celebrations, and other artifacts that are used to teach students knowledge, skills, morals, and values" (p. 108). It frequently takes the form of bulletin-board decorations, public displays, and tokens of appreciation, to name a few. Take advantage of workshop spaces or other publicly accessible space to incorporate culturally relevant symbols as an instrument for teaching, and use these symbols to help convey important information.

\section{Societal curriculum. Gay (2002) defines this type of} curriculum as "the knowledge, ideas, and impressions about ethnic groups that are portrayed in the mass media" (p. 109). Typically, these curricula provide inaccurate information and false conceptualization of various ethnic groups. Extension educators need to understand how media portray and manipulate ethnic groups and what curricula and instruction can do to counteract those influences (Gay, 2002).

\section{Cultural Caring and Developing a Learning Community}

Extension educators need to develop a learning environment or "classroom climate" that is conducive to learning for ethnically diverse students. Gay (2002) explains that pedagogical actions (pedagogy is the method and practice of teaching) are as important as curriculum design, and she calls for educators to use cultural scaffolding in teaching ethnically diverse students, which means "using their own cultures and experiences to expand their intellectual 
horizons and academic achievement" (p. 109). Extension educators need to demonstrate culturally sensitive caring and build culturally responsive learning communities by caring so much about the success of ethnically diverse students that they accept only exemplary achievement and work hard to ensure their students' success. (Foster, 1997; Kleinfeld, 1974, 1975).

A strategy to facilitate culturally responsive caring calls for teachers to develop a partnership with ethnically diverse students "that is anchored in respect, honor, integrity, resource sharing, and a deep belief in the possibility of transcendence" (Gay, 2000, p. 52). Extension educators frequently conduct needs assessments and develop advisory committees to ensure that their clientele are partners in programmatic decisions, but Extension educators must extend engagement beyond this practice. They must develop relationships in culturally diverse communities to build trust and promote a relationship of reciprocity, wherein there is a mutual interest for each other's success.

Developing these partnerships results in building learning communities among diverse learners, which is a critical element of culturally responsive teaching (Gay, 2002, 2018). It produces a learning culture centered on group functioning where everyone helps one another and everyone contributes to mutual gain. Multiple studies (Escalanté \& Dirmann, 1990; Fullilove \& Treisman, 1990; Sheets, 1995; Tharp \& Gallimore, 1988) demonstrate the value of this approach across various educational contexts and ethnic groups. Extension educators must understand how the different work styles may impede on academic success and need to understand how to develop more communal learning environments (Gay, 2002). They must also ensure that "personal, moral, social, political, cultural, and academic knowledge and skills are taught simultaneously" (p. 110). For example, Hispanic participants are taught their cultural heritages and positive ethnic identity development along with topics such as agriculture, horticulture, natural resources, nutrition, and community development. Extension educators should also ensure that their participants are learning about other ethnic groups as they learn about their own.

\section{Intercultural Communications}

According to Gay (2002), communication styles of different ethnic groups not only reflect cultural values, but also shape learning behaviors and should be considered when modifying educational interactions. The communications style of the majority of ethnic groups in the United States can be described as "more active, participatory, dialectic and multimodal" (Gay, 2002, p. 111). Participants from these groups are typically more engaged in providing prompts, feedback, and commentary and thrive in a setting where the roles of speaker and listener consistently shift and become interchangeable.

In addition, many African, Asian, Latino, and Native American Extension participants use what is called topicchaining communication, in which a significant amount of time is devoted to setting a social stage to the performance of an academic task. Ideas are communicated by "providing a lot of background information; being passionately and personally involved with the content of the discourse; using much indirectness (such as innuendo, symbolism, and metaphor) to convey ideas; weaving many different threads or issues into a single story; and embedding talk with feelings of intensity, advocacy, evaluation, and aesthetics" (Gay, 2002, p. 112). This style is categorized as more conversational and viewed as storytelling. It is important that Extension educators not only respect their participants as they use this style to communicate their ideas, but adopt it themselves to provide messages and deliver information in a way that resonates.

\section{Cultural Congruity in Classroom Instruction}

Gay (2002) asserts that culture is deeply entrenched in teaching, so educating ethnically diverse clients has to be "multiculturalized." Extension educators must match instructional techniques to the learning styles of diverse students where they use the information they acquire about the cultural characteristics of their clientele to establish a match. Learning styles in every ethnic group include eight key components (Gay, 2002):

- Preferred content

- Way of working through learning tasks

- Techniques for organizing and conveying ideas and thoughts

- Physical and social setting for task performance

- Structural arrangements of work, study, and performance space

- Perceptual stimulation for receiving, processing, and demonstrating comprehension and competence 
- Motivations, incentives, and rewards for learning

- Interpersonal interactional styles

Studies show (Gay, 2000; Spring, 1995) that these components can be achieved by creating learning communities built upon cooperative group-learning arrangements and peer coaching that match well with the communal culture systems of ethnic groups like African, Asian, Native American, and Hispanic groups. A large proportion of instruction time should be devoted to giving examples and scenarios to "demonstrate how information, principles, concepts, and skills operate in practice" (Gay, 2002; p. 113). Evidence demonstrates that if these examples are culturally relevant, they will have positive effects on the academic achievement of ethnically diverse students.

\section{Conclusion}

Extension educators must proactively take steps to develop programs that meet the needs of and are relevant for diverse audiences to ensure Extension remains relevant. The United States will continue to be the home of a large group of immigrants, so utilizing the best practices of culturally responsive teaching is critical. We recommend that Extension educators utilize the framework in the article to adapt their programs to extend their reach beyond their traditional audiences and achieve parity and achievement across a range of ethnic groups.

\section{References}

Banks, J. A., \& Banks, C. A. M. (Eds.). (2009). Multicultural education: Issues and perspectives. Hoboken, New Jersey: John Wiley \& Sons.

Escalanté, J., \& Dirmann, J. (1990). The Jaime Escalanté math program. Journal of Negro Education, 59(3), 407-423.

Flores, A., Lopez, M., \& Krogstad, J. (2019). U.S. Hispanic population reached new high in 2018 , but growth has slowed. Retrieved from https://www.pewresearch.org/ fact-tank/2019/07/08/u-s-hispanic-population-reachednew-high-in-2018-but-growth-has-slowed/

Foster, M. (1997). Black teachers on teaching. New York, New York: New Press.
Fullilove, R. E., \& Treisman, P. U. (1990). Mathematics achievement among African American undergraduates at the University of California, Berkeley: An evaluation of the Mathematics Workshop Program. Journal of Negro Education, 59(30), 463-478. Retrieved from http://www.physics. emory.edu/faculty/weeks/journal/treisman-jne90.pdf

Gay, G. (2000). Culturally responsive teaching: Theory, research, and practice. New York, New York: Teachers College Press.

Gay, G. (2002). Preparing for culturally responsive teaching. Journal of teacher education, 53(2), 106-116. Retrieved from http://citeseerx.ist.psu.edu/viewdoc/download?doi=10.1.1.4 $52.3431 \&$ rep $=$ rep $1 \&$ type $=$ pdf

Gay, G. (2018). Culturally responsive teaching: Theory, research, and practice (3rd ed.). New York, New York: Teachers College Press.

Hollins, E. R., King, J. E., \& Hayman, W. C. (Eds.). (1994). Teaching diverse populations: Formulating a knowledge base. Albany, New York: State University of New York Press.

King, J. E., Hollins, E. R., \& Hayman, W. C. (Eds.). (1997). Preparing teachers for cultural diversity. New York, New York: Teachers College Press.

Kleinfeld, J. (1974). Effects of nonverbal warmth on the learning of Eskimo and White students. Journal of Social Psychology, 92(1), 3-9. Retrieved from https://www.tandfonline.com/doi/abs/10.1080/00224545.1974.9923065

Kleinfeld, J. (1975). Effective teachers of Eskimo and Indian students. School Review, 83(2), 301-344. Retrieved from https://pubs.iseralaska.org/media/ f12320af-100b-48a9-bf9c-8c7b43ad46b7/1975_02EffectiveTeachersOfEskimoAndIndianStudents.pdf

Nieto, S., \& Bode, P. (2007). Affirming diversity: The sociopolitical context of multicultural education (7th ed.). Upper Saddle River, NJ: Allyn \& Bacon.

Pai, Y. (1990). Cultural foundations of education. New York, New York: Merrill/Macmillan

Radford, J., \& Noe-Bustamante, L. (2019). Facts on U.S. Immigrants. Retrieved from https://www.pewhispanic. org/2019/06/03/facts-on-u-s-immigrant/ 
Sheets, R. H. (1995). From remedial to gifted: Effects of culturally-centered pedagogy. Theory Into Practice, 34(3), 186-193. Retrieved from https://www.jstor.org/ stable/1476638

Smith, G. P. (1998). Common sense about common knowledge: The knowledge bases for diversity. Washington, DC: American Association of Colleges for Teacher Education.

Spring, J. (1995). The intersection of cultures: Multicultural education in the United States. New York, New York: McGraw-Hill.

Tharp, R. G., \& Gallimore, R. (1988). Rousing minds to life: Teaching, learning, and schooling in social context. Cambridge, UK: Cambridge University Press. 